\title{
DO INDIVIDUAL E DO COLETIVO: SOBRE APROXIMAÇÕES ENTRE O PENSAMENTo de FreUd E MARX
}

\author{
Patrícia Magri Granúzzio \\ Renata de Fátima Ceribelli²
}

RESUMO: o objetivo deste artigo é discutir a aproximação teórica entre duas vertentes distintas de pensamento que, inicialmente, pode parecer improvável: a psicanálise e o marxismo. O texto discorre sobre a reflexão da gênesis do problema político, interpretando sociedade e indivíduo como inter-relação da natureza humana, conectando, a partir desse princípio, o problema político e o problema psicológico, este se situando como base original daquele. Portanto, no entrecruzamento de sociedade, poder político e natureza humana, expande-se um campo de investigação que se abre a diversas possibilidades, inclusive à aproximação teórica entre as ideias de Marx e Freud. Dentre diversos autores que discutem o freudomarxismo e o posicionamento de Sigmund Freud, diante das ideias de Karl Marx, será dada exclusividade a Wilhelm Reich, Herbert Marcuse e a Ludwig Marcuse. Para uma crítica às ideias de Herbert Marcuse e análise da inter-relação entre marxismo e psicanálise, por sua vez, recorre-se ao filósofo marxista Louis Althusser e a outros analistas e críticos dessas mesmas ideias.

PALAVRAS-CHAVE: Marx. Freud. Sociedade. Poder Político. Natureza Humana.

\begin{abstract}
Com Copérnico, o homem deixou de estar no centro do universo. Com Darwin, o bomem deixou de ser o centro do reino animal. Com Marx, o bomem deixou de ser o centro da história (que, aliás, não possui um centro). Com Freud, o bomem deixou de ser o centro de si mesmo. Eduardo Prado Coelho
\end{abstract}

A aproximação teórica entre duas linhas distintas de pensamento, a psicanálise e o marxismo, em um primeiro momento, pode parecer impossível, porém, como bem observa Martin Miller (1998), as discussões sobre a relação entre

\footnotetext{
${ }^{1}$ Doutoranda em Educação na Universidade Metodista de Piracicaba - UNIMEP - Núcleo de Formação de Professores - Bolsista CAPES e Educadora de História da Rede Pública Estadual. pmgranuzzio@yahoo.com.br

2 Mestranda em Educação na Universidade Metodista de Piracicaba - UNIMEP - Núcleo de Formação de Professores - Bolsista CAPES - Educadora de Língua Portuguesa da Rede Pública Estadual e Gestora de Escola de Educação Infantil. renata_ceribelli@yahoo.com.br
} 
marxismo e psicanálise, na Rússia, datam do início do século XX, desenvolvidas pelo Instituto de Pesquisa Social de Frankfurt, ainda em 1929.

Para pensar na articulação entre esses dois campos do saber é necessário, antes de mais nada, aceitar que a origem de todo e qualquer problema político se encontra na própria natureza humana. Em segundo lugar, devemos ter em mente que as ciências estudam e pesquisam o que acontece na sociedade, e que esta é aquilo que as pessoas são, ou seja, ela é o que é, devido a seus cidadãos.

Tendo Sigmund Freud desenvolvido a tese de que nossa civilização só faz aumentar a infelicidade e as doenças psíquicas - como as diversas neuroses humanas - e estabelecido uma relação direta entre psicologia individual e social, permitiu que Wilhelm Reich e Herbert Marcuse, filósofos da chamada "teoria crítica" proposta pela Escola de Frankfurt, buscassem uma aproximação entre a psicanálise freudiana e o marxismo. Chamada de freudomarxismo, essa corrente de pensamento não incluía uma conjunção total, havia divergência em alguns pontos, sendo talvez o mais importante o fato de que o papel do capitalismo como origem das neuroses era visto de modo distinto por uns e outros. Paul Robinson (1971, p. 157) ressalta que não houve uma síntese das correntes teóricas, mas que Marcuse, ao unir Freud com Marx, “[...] transladou as categorias não-históricas e psicológicas do pensamento de Freud para as categorias eminentemente históricas e políticas do marxismo".

Como comenta Göran Therborn (2003), Reich (1977) levanta a questão das possíveis ligações entre a psicanálise de Freud e o materialismo de Marx e Engels, cuja resposta ele afirma permitir a discussão sobre as relações da psicanálise com a revolução proletária e a luta de classes, ainda que seu interesse específico estivesse no problema da liberação da sexualidade. Já Marcuse entende o marxismo como teoria social, não apenas se preocupando com questões econômicas, mas também com as necessidades humanas, voltando a atenção para uma “dimensão biológica", para as necessidades vitais instintivas, em um sentido amplo da palavra, para as necessidades "eróticas". Reich procura relacionar o conceito freudiano de repressão dos instintos ao conceito marxista de alienação econômica; estando articulado com uma ideologia anticapitalista, proposta pela teoria crítica, além de se referir aos aspectos qualitativos do trabalho e das relações humanas na sociedade, acrescenta-lhes uma dimensão psicanalítica.

O próprio Freud, discorrendo sobre os múltiplos interesses da psicanálise para as ciências não psicológicas, argumenta que o interesse filosófico reside no fato de que, a psicologia, tendo a filosofia como base, é a disciplina em que a personalidade do homem de ciência desempenha o maior papel. Segundo Freud, a descoberta de atividades anímicas inconscientes obriga a filosofia a tomar partido e 
considerar a hipótese de que a relação entre o psíquico e o físico é intrínseca; para ele, o inconsciente tem extraordinária afinidade com os fenômenos conscientes. Com a psicanálise sendo uma psicografia da personalidade humana, vê-se, assim, seu interesse sociológico também; conhecendo as unidades afetivas, os complexos inerentes a todo indivíduo, iniciamos os estudos das transformações, gerados pelas forças instintivas, e os resultados finais a que cada pessoa chegou (FREUD, 1974, p. 209-210).

Preocupado sempre com a necessidade da transformação radical da sociedade capitalista e com a emancipação completa do ser humano, Marcuse se voltou primeiramente para as ideias de Marx e depois para as de Freud, compreendendo que, sem uma transformação radical da consciência e do inconsciente, das necessidades e aspirações humanas, as revoluções estariam para sempre votadas ao fracasso. Desse modo, em sua obra Eros e Civilização, ele discute e analisa a derrota das revoluções em termos econômicos, políticos, sociais, históricos e psicológicos, levantando a hipótese de que é a repressão das pulsões de vida (Eros) que cria indivíduos aptos a aceitarem uma sociedade repressiva e a temerem sua própria libertação (LOUREIRO, 2005).

Seguindo essa linha de pensamento, teremos que todo problema político é, em sua base original, resultante de um problema psicológico. Se tomarmos por fundamento que as relações humanas nada mais são do que contratos firmados entre as pessoas, para uma discussão sobre problemas políticos, podemos recorrer tanto a Thomas Hobbes (1588-1679) quanto a John Locke (1632-1704).

Ao desenvolver suas teses políticas liberais, Locke sustenta a tese de que o estado de sociedade e, consequentemente, o poder político, não nascem da tradição ou da força, mas do consentimento expresso dos governados, do pacto firmado entre os humanos. Antes disso, para Locke, homens e mulheres viveriam em estado natural. As ideias sobre estado natural já tinham sido defendidas por Thomas Hobbes para justificar o absolutismo. Assim como Hobbes, Locke afirma que o contrato social firmado pelos cidadãos é que permitiu a passagem do estado natural para o estado civil. Porém, diferente daquele é sua concepção acerca desse trinômio. Enquanto Hobbes, seguindo a doutrina aristotélica, enfatiza que a sociedade precedeu o indivíduo, Locke acredita ser a existência do indivíduo anterior ao surgimento da sociedade e do Estado (ARANHA; MARTINS, 1993, p. 218-219).

De acordo com Locke (1978, p. 36), os seres humanos viviam originalmente num estágio pré-social e pré-político, caracterizado pela mais perfeita liberdade e igualdade, denominado estado de natureza. Esse estado de natureza seria de liberdade e não de licenciosidade, sendo que ninguém deveria prejudicar a outrem na vida, na saúde, na liberdade ou nas posses e, se assim o fizesse, seria passível de castigo, pena e morte. 
Quanto ao contrato social, Hobbes entende que os homens firmam entre si um pacto de submissão por meio do qual preservam suas vidas e transferem a um terceiro (homem ou assembleia) a força coercitiva da comunidade, trocando voluntariamente sua liberdade pela segurança do Estado. Para Locke, o que aconteceu foi um pacto de consentimento em que os homens concordaram livremente, visto que, no estado de natureza, estavam expostos a inconvenientes; para evitar tais inconvenientes, teriam criado a sociedade política - um pacto social cujo objetivo seria a preservação da vida, da liberdade e da propriedade, bem como reprimir as violações a esses direitos naturais. Segundo ele, assim procedendo, os homens não estariam renunciando aos seus próprios direitos naturais em favor do poder dos governantes. O chefe do Estado seria um mandatário do povo, cuja vontade deveria ser soberana (ARANHA; MARTINS, 1993, p. 218-219; MELLO, 1989, p. 80-89).

Entrecruzando-se, assim, sociedade, poder político e natureza humana, temos um campo de investigação aberto a diversas possibilidades, inclusive à aproximação teórica entre ideias de Marx e Freud.

Antes de estabelecermos relações entre temas trabalhados por Freud (como libido, pulsão, recalcamento e outros) e temáticas marxistas (como estrutura econômica, exploração de uma maioria por uma minoria, sistema de produção capitalista, socialismo), é importante que atentemos às críticas de Reich, diante daqueles que se opõem ao movimento que propõe a aliança intelectual entre Freud e Marx. Conforme Reich, os que assim procedem ou argumentam que Freud desprezava completamente o problema central da sociologia de Marx, a luta de classes, ou argumentam que a psicanálise é apenas um método psicológico que procura descrever e explicar a vida psíquica e não um sistema filosófico, não completam, dessa forma, a concepção materialista da história (REICH, 1977, p.15-18).

Ludwig Marcuse (1961) afirma que Freud considerava Marx uma grande ameaça, e o que acontecia na Rússia, uma ilusão perigosa para a humanidade. Marcuse ressalta ainda que Freud somente desenvolveu conceitos psicológicos fundamentados nas relações entre os homens, desinteressando-se pelos fatores sociais para além da situação instintiva. Isso, segundo ele, teria ocorrido a Freud, em um primeiro momento, por observar unicamente os novos domínios que lhe requeriam exclusiva atenção. Entretanto, mais tarde, teria ignorado os elementos sociais deliberadamente, porque reconhecera que ao médico era acessível um trauma especial, mas já não o era a doença social. De acordo com Marcuse, Freud se recusava a incluir no seu domínio aquilo que o médico não pode alterar, o modo com que a sociedade de classes se estabelece. Para ele, Freud descobriu a saúde no homem doente, da mesma maneira que Marx a descobriu na sociedade enferma, considerando-se utopia e saúde, moral e saúde como conceitos que se aproximaram muito. A "saúde" para Freud, quase sinônima de razão, era apenas 
um compromisso, um meio termo muito áureo, que ficava entre a plenitude e o recalcamento; era um compromisso, mas esse compromisso era um autêntico ideal (MARCUSE, 1961, p. 60; p. 106).

Marcuse salienta que o próprio Freud sempre foi prudente, por um lado, no que se refere à transposição da psicologia individual para a psicologia coletiva, todavia, por outro lado, tentou esclarecer a história do indivíduo que decorre entre os dois e os cinco anos e a correspondente infância dos grupos humanos de modo que os dois processos reciprocamente se relacionavam. Conforme Marcuse, aproximado-se das ideias de Hegel, no tocante a noções de homem livre, o Paraíso era o mundo antes da renúncia aos instintos. Freud atribuía à renúncia ao instinto as funestas consequências históricas, sendo uma delas a sociedade constituída por classes (MARCUSE, 1961, p. 104-105).

Se Freud via a deformação do humano, a origem do mal no destino biossociológico do indivíduo, na relação ambivalente, primeiro com o pai, depois com o chefe, Marx encontrava a origem do mal na separação entre senhores e escravos. Ambos os conflitos se processam há milênios e, para Marcuse (1961, p. 112), ambos os pensadores temiam que se apontasse o indicador para demônios tão terrenos como os são as doenças dos indivíduos e as doenças da sociedade, porque, assim, eles podem se alastrar e conduzir a todos em uma direção indesejável; dessa forma, sonhavam ambos em reformar e melhorar o mundo.

Por trás de toda contenda havida entre as ideias de Freud e Marx, Marcuse esclarece que Freud reconhecera que a cultura fora até os seus dias apenas uma cultura burguesa, deixando insatisfeito um grande número de excluídos e impelindo-os à revolta. Esse analista das ideias de Freud comenta, igualmente, que este reconhecia que "[...] uma alteração real nas relações entre o homem e a propriedade seria incontestavelmente mais vantajosa do que qualquer mandamento ético" e que Marx pregava que "[...] os dispositivos da sociedade não deveriam dificultar tanto ao indivíduo um viver humano” (MARCUSE, 1961, p. 113). Devemos, no entanto, observar que Freud se refere às relações entre homem e propriedade e não à abolição da propriedade privada.

Em sua obra O mal estar na civilização, Freud (1974) destaca:

Os comunistas acreditam ter descoberto o caminho para nos livrar de nossos males. Segundo eles, o homem é inteiramente bom e bem disposto para com o seu próximo, mas a instituição da propriedade privada corrompeu-lhe a natureza. A propriedade da riqueza privada confere poder ao indivíduo e, com ele, a tentação de maltratar o próximo, ao passo que o homem excluído da posse está fadado a se rebelar hostilmente contra seu opressor. 
[...] Não estou interessado em nenhuma crítica econômica do sistema comunista; não posso investigar se a abolição da propriedade privada é conveniente ou vantajosa. Mas sou capaz de reconhecer que as premissas psicológicas em que o sistema se baseia são uma ilusão insustentável. Abolindo a propriedade privada, privamos o amor humano da agressão de um de seus instrumentos, decerto forte, embora, decerto também, não o mais forte; de maneira alguma, porém, alteramos as diferenças em poder e influência que são mal empregadas pela agressividade, nem tampouco alteramos nada em sua natureza.

[...] A agressividade não foi criada pela propriedade. Reinou quase sem limites nos tempos primitivos, quando a propriedade ainda era muito escassa [...].

No olhar de Marcuse, a grande encruzilhada em que Freud se separava de Marx não é o ponto no qual se insere o materialismo, pois Freud não teria subestimado o poder dos motivos econômico-políticos que estão na raiz de todas as criações do espírito: o que Freud teria recusado seria o idealismo filosófico. Para Freud, a ilusão marxista estava em acreditar que as tendências agressivas dos seres humanos provinham da sociedade capitalista, o que para aquele eram simplesmente inatas e impraticáveis de se querer suprimir, mesmo acreditando no desaparecimento das guerras. Via em Marx um grande causador de calamidades e no marxismo a destruição da liberdade de pensamento, apesar de reconhecer que este propiciava uma legislação sexual mais livre.

Freud não reconhecia como o comunismo e a psicanálise podiam se dar bem, porque o primeiro é demasiado dogmático, mesmo sendo a psicologia de Freud uma Psicologia social, uma ciência que não deve ser burguesa, mas lidar unicamente com fatos que são verdadeiros em toda parte, apesar de os resultados obtidos serem válidos relativamente a uma determinada sociedade; em qualquer outra, de aspectos diferentes, os resultados diferem. Diferenças essenciais consoantes às classes sociais e a frequência das nevroses são encontradas, porém, Freud não achava que as necessidades de um ser vivente são suscitadas pelas alterações do meio ambiente e muito menos que as necessidades do homem são criadas pelo trabalho (MARCUSE, 1961, p. 107-120).

Nem todos os marxistas são radicalmente contra a psicanálise, deixando de lado a querela entre o fato de ser esta última defensora do antipartidarismo e disponível para novas experiências e novas hipóteses. Wilhelm Reich foi um pioneiro ao ver na psicanálise uma contribuição para que o materialismo dialético interpretasse a ideologia de uma determinada sociedade. Segundo ele, a psicanálise, não sendo um sistema filosófico, não é capaz de engendrar um outro sistema, pois é apenas um método psicológico que, com meios científicos, procura descrever e explicar a vida psíquica, considerada um domínio particular da natureza. 
Para Reich, a psicanálise não poderia substituir nem completar a concepção materialista da história. Parecendo que o fenômeno da consciência de classe lhe é dificilmente acessível e os problemas tais como o movimento de massas, a política, a greve, que são do domínio da sociologia, escapam ao método psicanalítico, de sorte que Reich esclarece que a psicanálise pode desempenhar o papel de ciência auxiliar, sob a forma de psicologia social. Assim, a psicanálise é auxiliar da sociologia marxista e não do marxismo como método de investigação (REICH, 1973, p. 18-21).

A teoria das pulsões constitui um dos pontos centrais da psicanálise, o seu elemento mais sólido é a teoria da libido, a da dinâmica da pulsão sexual. Pulsão é uma noção-limite entre o psíquico e o somático; libido é a energia do instinto sexual. Para Reich, Freud teria feito tábua rasa da concepção segundo a qual a pulsão sexual só nasce na puberdade, mostrando que, desde o nascimento, a libido passava por determinados estádios de desenvolvimento antes de atingir o estádio da sexualidade genital. Cada uma das fases de desenvolvimento da libido é caracterizada pelas condições de existência da criança. Imbuída de moral burguesa, a ciência teria desprezado esse fato, confirmando a concepção popular da pureza da criança (REICH, 1973, p. 37-40).

A existência social do indivíduo limita a satisfação das pulsões. Ao enunciar o princípio da realidade, Freud teria reunido nele todas as limitações e todas as pressões sociais que tendem a menosprezar as necessidades ou a retardarlhes a satisfação. O princípio da realidade para nós, atualmente, é o princípio da sociedade capitalista, baseada na economia privada. Esse princípio "[...] impõe ao proletário uma extrema limitação das suas necessidades, não sem invocar para este fim as obrigações religiosas de humildade e de modéstia. Impõe também a forma sexual monogâmica e ainda muitas outras coisas". Essa imposição serve para que a classe dominante mantenha o seu poder. Aceitando esse princípio imposto pela classe dominante, o proletário o admite como válido em nome da cultura, admitindo a sua exploração e a sociedade capitalista (REICH, 1973, p. 46-48).

Entre tantas descobertas e teorias, Freud contestou a concepção de livre-arbítrio, concordando com Engels de que o livre-arbítrio não é mais do que a aptidão para poder decidir com conhecimento de causa. Para Freud, a estrutura do aparelho psíquico estava dividida em infra-eu, eu e super-eu, também traduzido para a língua portuguesa como infra-ego, ego e super-ego (ou ainda id, ego e superego). O ego se identifica à nossa consciência; o superego seria a nossa consciência moral, ou seja, os princípios sociais e as proibições impostas pela sociedade e que nos são inculcadas logo nos primeiros anos de vida e que nos acompanham de forma inconsciente por toda a vida; o id são os impulsos múltiplos da libido, dirigidos sempre para o prazer. $\mathrm{O}$ id exprime a participação 
do biológico na personalidade, sendo constituído em parte pelo inconsciente por coisas recalcadas (por autoconservação ou por ordem social) ou sublimadas, desviadas para outras atividades sociais. A oposição entre prazer e princípio de realidade dificulta ao homem ser feliz, afinal, está constantemente reprimindo seus instintos sexuais (FREUD, 1974).

Sob a influência do mundo exterior, o superego começa a se desenvolver no aparelho psíquico, inibindo-o e, transformando-se em um entrave moral (REICH, 1973, p. 91).

\begin{abstract}
Se a civilização impõe sacrifícios tão grandes, não apenas à sexualidade do homem, mas também à sua agressividade, podemos compreender melhor porque lhe é difícil ser feliz nessa civilização. Na realidade, o homem primitivo se achava em situação melhor, sem conhecer restrições de instinto. Em contrapartida, suas perspectivas de desfrutar dessa felicidade, por qualquer período de tempo, eram muito tênues. O homem civilizado trocou uma parcela de suas possibilidades de felicidade por uma parcela de segurança. (FREUD, 1974).
\end{abstract}

Reich afirma que, se os conflitos interiores e exteriores determinam, conforme explicado por Freud, o desenvolvimento, a existência social enche com suas representações e conteúdos tanto os objetivos pulsionais quanto os entraves morais. Desse modo, a psicanálise confirmaria inteiramente a tese desenvolvida por Marx de que é a existência social que determina a consciência, isto é, as representações, objetivos e pulsões, ideologias morais etc. - e não o contrário. Haveria, portanto, concordância entre as ideias de que os homens fazem a sua própria história, mas isso se dá em condições determinadas e com determinados pressupostos iniciais, de natureza social (REICH, 1973, p. 92-93).

Reich insiste em que a psicanálise, como qualquer outro fenômeno social, está ligada às relações de produção, sendo um produto da era capitalista, uma reação às condições culturais e morais em que vive o homem social, uma reação às condições sexuais tal como resultam das ideologias religiosas. Para ele, se o marxismo foi a tomada de consciência das leis econômicas, da exploração de uma maioria por uma minoria, a psicanálise foi a tomada de consciência da repressão sexual social. O que diferencia uma expressão de outra é que, enquanto uma classe explora e domina ideologicamente a outra, ambas passam por problemas de recalcamento e sublimação sexual.

Reich vai além das aproximações e diferenças entre uma teoria e outra. Afirma que a existência da sociedade capitalista simplesmente impede a psicanálise de ser verdadeira, visto que está calcada em valores burgueses, como o casamento, a educação e a moral sexual, que impedem a cura psicanalítica radical das nevroses. 
Tendo que se adaptar à sociedade burguesa, a psicanálise estaria fadada à servidão social e à morte (REICH, 1973, p. 116-121). A economia e sociedade socialista abririam caminhos para um livre desenvolvimento do intelecto e da sexualidade, possibilitando, assim, que a psicanálise sobrevivesse.

Para Louis Althusser (1985), Reich cometeu um erro, ao tentar relacionar as ideias de Marx com as de Freud. Segundo Althusser, Reich, prisioneiro que era do preconceito ideológico do monismo, considerando assim que não havia duas substâncias, mas uma só e que esta possui dois atributos - a matéria e a energia -, buscou afinidades entre os dois pensadores e as duas teorias, baseando-se em uma identidade de objeto, ou seja, querendo identificar os efeitos do inconsciente isolados por Freud com os efeitos da luta de classes apontados por Marx. Althusser comenta que há grande diferença entre objeto real e objeto-de-conhecimento. Os objetos teóricos de Freud e de Marx, enquanto objetos teóricos, são objetos de conhecimento e, como tais, irredutíveis ao objeto real, não havendo assim homogeneidade entre o pensamento de Freud e Marx (ALTHUSSER, 1985, p. 76).

O que Althusser vê de comum entre as ideias de Freud e Marx é, antes de mais nada, que ambos, diante de um mundo dominado pelo idealismo e pelo mecanicismo, oferecem exemplos de pensamento materialista e dialético. Outro ponto importante apontado por Althusser é que as duas teorias têm em comum o fato de serem conflituosas, exigindo constantemente ataques e críticas, tentativas de revisão e anexação e, por vezes, cisão de seus adeptos, atitudes que por si provam elas serem verdadeiras por final e, muitas vezes, exigindo da sociedade tentativas de neutralização.

O que nos permitiria ver aproximações entre as ideias de Freud e de Marx é pensar que tanto o aparelho psíquico quanto o aparelho ideológico não são construídos por uma unidade centrada, mas um conjunto de instâncias constituídas pelo jogo do recalque inconsciente e pelo jogo das relações sociais. A formação subjetiva do indivíduo e a formação social seriam um sistema de instâncias sem centro, com unidades de funcionamento conflituosas; ambas as teorias buscam a verdade sobre o homem (ALTHUSSER, 1985, p. 75-93).

Vasconcelos (2005), concordando em parte com Althusser, afirma que os freudomarxistas estavam ainda presos a uma utopia romântica de uma sociedade que conseguiria harmonizar desejos e formas de sociabilidade. Para ele, o freudomarxismo de Marcuse e de Reich revelaram contradições e problemas, sendo, o principal, a crença na desalienação integral do homem, o que teria resultado na tentativa de submeter e sociologizar o freudismo e de desmistificar o seu pessimismo cultural. Reich e Marcuse, ao tentarem conciliar libido e cultura, as políticas sexuais e culturais, teriam empreendido uma normatização 
nesses campos, induzindo à difusão do que se acreditava serem as formas mais revolucionárias de vivência do corpo, da sexualidade, do prazer, da subjetividade, da cultura e das relações comunitárias.

Para Vasconcelos, mesmo presos a uma utopia romântica, Reich e Marcuse teriam avançado na análise dos mecanismos culturais, ideológicos e particularmente subjetivos, afetivos e associados à corporeidade e sexualidade da sociedade capitalista e de classes - sobretudo do nazifacismo e da sociedade de consumo - para a manutenção e recriação das relações de poder, dominação e, principalmente, de sedução e consenso, esboçando, assim, uma análise mais sistemática das instituições e dos aparelhos ideológicos do Estado e da sociedade civil em sociedades complexas. Vasconcelos acrescenta que Adorno propôs uma interação mais complexa e não linear entre marxismo e psicanálise, e entre o desejo e o social, não reduzindo o freudismo ao marxismo e vice-versa, de modo a recusar-se a uma "síntese utópica" entre civilização e pulsão, cura, normalidade e totalidade, aceitando-as como contradição permanente da vida humana.

Deve-se salientar, não obstante as críticas contrárias ao freudomarxismo de Marcuse e Reich, tanto para eles quanto para outros pensadores da Escola de Frankfurt, como Max Horkheimer - apesar de sua crítica ao pessimismo de Freud, incompatível com as esperanças revolucionárias trazidas pelo marxismo -, a psicanálise permitiu um novo olhar para as questões marxistas, sejam elas sobre os efeitos sociais em um indivíduo, sejam sobre os efeitos sociais nos grupos, sobre o poder e aceitação da autoridade ou até mesmo sobre as maneiras que se buscam prazer e satisfação para seus impulsos.

Therborn (2003) vai ainda mais além, ao afirmar que, se por um lado, o objetivo dos socialistas consistia em subordinar a produção, a luta do homem contra a natureza, a um controle racional e coletivo numa comunidade livre, por outro lado, o freudomarxismo agrega uma outra dimensão a esse objetivo: socialismo significa, agora também, a felicidade. Como exemplo, cita a contribuição de Erich Fromm à teoria crítica, quando este envolve a análise do indivíduo, família, repressão sexual, economia e o contexto social do indivíduo, integrando trabalhos de Freud e Marx. Fromm argumenta que há instintos básicos que acabam por ser forças motrizes para o comportamento humano, mas que são adaptados, ativa e passivamente, para a realidade social. Ele combina abordagens sociais e psicológicas com o materialismo de Marx, ou seja, as forças psicológicas e instintivas com os efeitos das forças econômicas e materiais na vida humana (THERBORN, 2000).

A aproximação entre marxismo e psicanálise foi realizada por Reich e aprofundada por Marcuse, ambos identificando o recalcamento com a repressão social, com a diferença de que Reich nega uma parte substancial da teoria 
freudiana, a das pulsões, de modo a mostrar que o homem é associal, não por natureza, mas por causa da própria repressão social, enquanto Marcuse regressa aos dados biológicos e ao biologismo de Freud, entendendo que, como afirma Anthony Elliot (2004), a emancipação do indivíduo poderia ser a reconciliação entre cultura, natureza, prazer inconsciente e a realidade.

Como bem observa Carneiro (2008), não devemos confundir maisrepressão como uma tradução da mais-valia marxista, no idioma freudiano. $\mathrm{O}$ princípio de desempenho é um fenômeno das sociedades industriais avançadas; a mais-repressão é localizada na história da dominação, quer feudal, quer capitalista ou patriarcal. Desse modo, Marcuse não propõe o fim total da repressão, mas questiona o grau de repressão necessário ao atual estágio de nossa civilização (CARNEIRO, 2008, p. 224). O próprio Marcuse, em Eros e Civilizaçãa, estabelece as diferenças entre repressão e mais-repressão: uma seria a repressão básica, as modificações dos instintos necessários à perpetuação da raça humana em civilização; a outra constituiria as restrições requeridas pela dominação social (MARCUSE, 1975, p. 50).

Nem Freud, nem Marx, Reich ou qualquer outro até agora respondeu como o poder da autoridade e a mais-repressão podem ser eliminados, possibilitando a existência de uma civilização mais feliz, porém, Marcuse ressalta que “[...] Freud tinha razão; a vida é má, repressiva, destrutiva mas não é assim tão má, repressiva, destrutiva. Há também os aspectos construtivos, produtivos. A sociedade não é só isto, mas também aquilo; o homem não é somente contra si mesmo, mas também por si mesmo" (MARCUSE, 1975, p. 214).

GRANÚZZIO, P. M.; CERIBELLI, R. F. The individual and the collective: on approximations between the thinking of Freud and Marx. Trans/Form/Ação, Marília, v. 34, n.2, p. 71-84, 2011.

ABSTRACT: The aim of this paper is to discuss the theoretical approach between two distinct strands of thought that initially may seem unlikely: psychoanalysis and Marxism. The text is about the reflection of the political genesis of the problem, interpreting society and individual as the interrelationship of human nature, connecting from this principle, the political problem and the psychological problem that is standing as the original basis of that. Therefore, the intersection of society, political power and human nature, it expands a field of research that opens several possibilities, including the theoretical approach between the ideas of Marx and Freud. Among several authors who discuss the freudomarxismo and positioning of Sigmund Freud on the ideas of Karl Marx will be given exclusivity to Wilhelm Reich, Herbert Marcuse and Ludwig Marcuse. For a critique of ideas of Herbert Marcuse and analysis of the inter-relationship between Marxism and psychoanalysis, in turn, refers to the Marxist philosopher Louis Althusser and other analysts and critics of those ideas.

KEYWORDS: Marx; Freud. Society. Political Power. Human Nature. 
GRANÚZZIO, P. M.; CERIBELLI, R. F.

\section{REFERÊNCIAS}

ALTHUSSER, L. Freud e Lacan. In: Marx e Freud: introdução crítica-histórica. Rio de Janeiro: Graal, 1985.

ARANHA, M. L. A.; MARTINS, M. H. P. Filosofando: Introdução à Filosofia. São Paulo: Moderna, 1993.

CARNEIRO, S. R. G. O Discurso Ontológico e a Teoria Crítica de Herbert Marcuse - Gênese da Filosofia da Psicanálise (1927- 1955). 2008. 258 f. Dissertação (Mestrado em Filosofia) - Faculdade de Filosofia, Letras e Ciências Humanas da Universidade de São Paulo, São Paulo, 2008.

ELLIOTT,A. Social Theory Since Freud - Traversing Social Imaginaries. Kentucky/USA: Routledge, 2004.

FREUD, S. O Mal-Estarna Civilização. (In: Edição Standard Brasileira das Obras Psicológicas Completas de Sigmund Freud, Vol. XXI) Rio de Janeiro: Imago, 1974. Disponível em: <http://www.cefetsp.br/edu/eso/filosofia/malestar.htmL>. Acesso em: 25 jul. 2008.

. O ego e o id. [1923] (In: Edição Standard Brasileira das Obras Psicológicas Completas de Sigmund Freud, Vol. XXI) Rio de Janeiro: Imago, 1974. Disponível em: < http://www. www.cefetsp.br/edu/eso/filosofiafreud19.rtf>. Acesso em: 25 jul. 2008.

. O interesse da psicanálise para as ciências não psicológicas, Edição Standard Brasileira das Obras Psicológicas Completas. Rio de Janeiro, Imago, 1974. v.13.

LOCKE, J. Carta acerca da tolerância; Segundo tratado sobre o governo; Ensaio sobre o entendimento bumano. São Paulo: Abril Cultural, 1978. (Os pensadores).

LOUREIRO, I. Herbert Marcuse - anticapitalismo e emancipação. Trans/Form/Ação, Marília, v. 28, n. 2, 2005. Disponível em <http://www.scielo.br/scielo.php?script=sci_ arttext\&pid=S0101- 1732005000200001\&lng=pt\&nrm=iso $>$. Acesso em: out. 2010.

MARCUSE, H. Eros e Civilização - uma interpretação filosófica do pensamento de Freud. Tradução de Álvaro Cabral. Rio de Janeiro: Zahar, 1975.

MARCUSE, L. Freud e a psicanálise [Sigmund Freud]. LBL Enciclopédia. Lisboa: Livros do Brasil, 1961.

MELLO, L. I. A. John Locke e o individualismo liberal. In: WEFFORT, F. (Org.). Os clássicos da política. São Paulo: Ática, 1989, p. 80-89.

MILLER, M. Frend and the Bolsheviks: Psychoanalysis in imperial Russia and the Soviet Union. New Haven, CT: Yale University Press, 1998.

REICH, W. Materialismo dialético e psicanálise. 2. ed. Tradução de Joaquim José Moura Ramos. Lisboa: Presença, 1977.

ROBINSON, P. A Esquerda Freudiana. Tradução de Álvaro Cabral. Rio de Janeiro: Civilização Brasileira, 1971. 
THERBORN, G. A escola de Frankfurt. Contribuição à teoria crítica. Revista Novos Rumos, número 39, ano 18, 2003. Disponível em: <http://www.institutoastrojildopereira.org.br/ novosrumos/artigo_show.asp?var_artigo $=65>$. Acesso em: set. 2010.

Critical Theory. In: Sociology 319 (março 2000). Disponível em: < http://uregina. $\mathrm{ca} /$ gingrich/m900.htm >. Acesso em: set. 2009.

VASCONCELOS, E. M. Românticos, exploradores do inconsciente e revolucionários: polêmicas históricas, desafios teóricos e suas implicações atuais. Mnemosine (UERJ). Rio de Janeiro, vol. 1, n. 2, p. 119-187, 2005. Disponível em: < http://www.cliopsyche.cjb.net/ mnemo/index.php/mnemo/article/view/143/297>. Acesso em: ago. 2010.

Recebido em: 4 de fevereiro de 2011

Aprovado em: 12 de junho de 2011

Trans/Form/Ação, Marilia, v. 34, n. 2, p. 71-84, 2011 